\title{
Posterior Lumbar Interbody Fusion versus Posterolateral Fusion in Surgical Treatment of Lumbar Spondylolithesis
}

\author{
Khaled Ismail Abdelaziz ${ }^{1}$, Radwan Nouby², Mohammad Fekry Elshirbiny1, \\ Ahmed Salaheldin Mahmoud1 \\ ${ }^{1}$ Department of Neurosurgery, Faculty of Medicine, Aswan University, Aswan, Egypt \\ ${ }^{2}$ Department of Neurosurgery, Faculty of Medicine, Assiut University, Assiut, Egypt \\ Email: ${ }^{* k h a l e d i s 2020 @ y a h o o . c o m ~}$
}

How to cite this paper: Abdelaziz, K.I., Nouby, R., Elshirbiny, M.F. and Mahmoud, A.S. (2020) Posterior Lumbar Interbody Fusion versus Posterolateral Fusion in Surgical Treatment of Lumbar Spondylolithesis. Open Journal of Modern Neurosurgery, 10, 135-145.

https://doi.org/10.4236/ojmn.2020.101014

Received: December 3, 2019

Accepted: December 27, 2019

Published: December 30, 2019

Copyright $\odot 2020$ by author(s) and Scientific Research Publishing Inc. This work is licensed under the Creative Commons Attribution International License (CC BY 4.0).

http://creativecommons.org/licenses/by/4.0/

(c) $\underset{\mathrm{By}}{\text { (i) Open Access }}$

\begin{abstract}
Background: The optimal surgical technique for lumbar spondylolithesis remains debated. Although posterior lumbar interbody fusion (PLIF) theoretically offers more advantages than posterolateral lumbar fusion (PLF), the evidence remains inconclusive. Aim: The aim of this study is to compare the clinical and functional outcomes of PLIF versus PLF in patients with lumbar spondylolithesis. Patients and Methods: We enrolled 38 patients with lumbar spondylolithesis (degenerative and isthmic) who underwent PLIF $(\mathrm{N}=$ 19) or PLF $(\mathrm{N}=19)$. We collected operative data and performed follow-up for 12 months after the surgery. The collected data were analyzed using the SPSS software to detected significant differences between both groups. Results: The PLF and PLIF groups exhibited similar pre-operative characteristics between both groups in terms of age $(p=0.57)$, sex $(p=0.73)$, clinical presentation $(\mathrm{p}=1)$, required levels of fixation $(\mathrm{p}=1)$, pre-operative VAS score $(\mathrm{p}=0.43)$ or muscle weakness $(\mathrm{p}=1)$. However, the PLIF group had significantly more blood loss and longer operative time than the PLF group. Moreover, both groups had similar levels of postoperative pain (up to six months after surgery), and post-operative complications. The rates of arthrodesis were higher in PLIF group than PLF group within six months while no significant difference within 12 months of follow-up. Conclusion: In our comparative study, we achieved comparison between pedicle screw fixation with posterolateral fusion alone (PLF) in compare with pedicle screw fixation with posterior lumbar interbody fusion (PLIF). Results indicate better results of fusion rate in PLIF as regards arthrodesis with slightly more rate of complication than PLF. So we recommend PLIF in cases of lumbar spondylolithesis than PLF.
\end{abstract}




\section{Keywords}

Arthrodesis, Lumbar Spondylolithesis, Posterior Lumbar Interbody Fusion (PLIF), Posterolateral Fusion (PLF)

\section{Introduction}

Spondylolithesis is defined as sagittal subluxation of the vertebral body over the other, and is characterized by failure of the three-column support [1]. Surgery is usually indicated in cases of disabling symptoms, neurological deficits and progressive conditions. However, to date, the optimal surgical treatment for lumbar spondylolithesis remains debated [2]. The surgical approach used to be dominant is posterolateral lumbar fusion (PLF); however, this technique depends mainly on posterior vertebral fixation with lack of anterior support and may interfere with spinal biomechanics [3]. Therefore, another approach (posterior lumbar interbody fusion: PLIF) has been argued to be superior to the traditional PLF approach [4] [5] [6] [7] [8].

Theoretically, PLIF offers more advantages than PLF as indirect foraminal decompression, anterior column support, restoration of lordosis, and maintaining the intervertebral disc height [9]. Moreover, the cancellous bone of the vertebral body is a better fusion bed in comparison to the surgically traumatized paraspinal musculature. It provides a greater area for contact increasing the rate of fusion [10]. Further, PLIF evacuates the disc, enlarging the neural foramina and reducing the probability of nerve root compression. Due to these advantages, PLIF is supposed to provide better fusion, normal sagittal contour and spinal biomechanics [3].

However, the literature compares PLF and PLIF in treatment of spondylolithesis. Several author groups considered PLIF as a superior surgical approach to PLF [4] [5] [6] [7] [8]. However, some studies found no evidence of significant benefits for PLIF over PLF. Fritzell and colleagues performed a randomized study that concluded no significant difference between both surgical approaches [11]. Similar results were observed in the studies by Kim et al. [12], Videbaek et al. [13], and Jacobs et al. [14]. Based on the controversy cited above, this study attempted to determine the optimal surgical technique for lumbar spondylolithesis by comparing PLIF and PLF regarding functional and operative outcomes.

\section{Patients and Methods}

\subsection{Patients}

We conducted a prospective case series at the Neurosurgery Department, Aswan University Hospital (Aswan, Egypt) from January 2017 to December 2018. Thirty-eight patients diagnosed with lumbar spondylolithesis who were undergoing PLIF and PLF. The study protocol was approved by the Ethical Research committee at Aswan University Hospital and all included patients signed an in- 
formed written consent before participation. The criteria for inclusion were: the presence of back pain and radicular pain unresponsive to conservative treatment with lumbar spine instability (presence of segmental instability in the images, recurrent surgery with isthmic or degenerative type at the same level). Patients with degenerative and isthmic types of spodylolithesis and of both sexes between 18 and 70 years old were included. We excluded patients above 70 years old and below 18 years old, those who were not fit for surgery and patients with debilitating diseases, malnutrition or osteoporosis.

\subsection{Preoperative Assessment}

All patients underwent sufficient history taking, neurological examination (lower limb motor evaluation, local back examination, and straight leg raising test), routine lab investigations, and imaging (plain x-ray antero-posterior, lateral and dynamic films "flexion/extension, CT, and MRI lumbosacral spine (Figure 1)

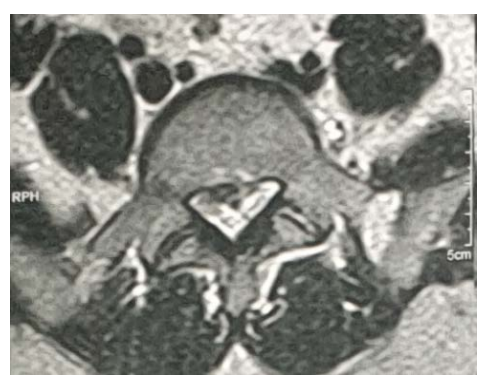

(a)

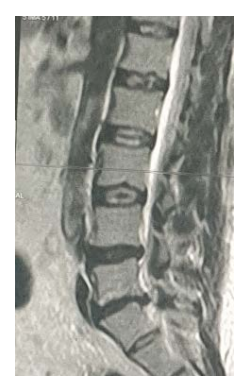

(b)
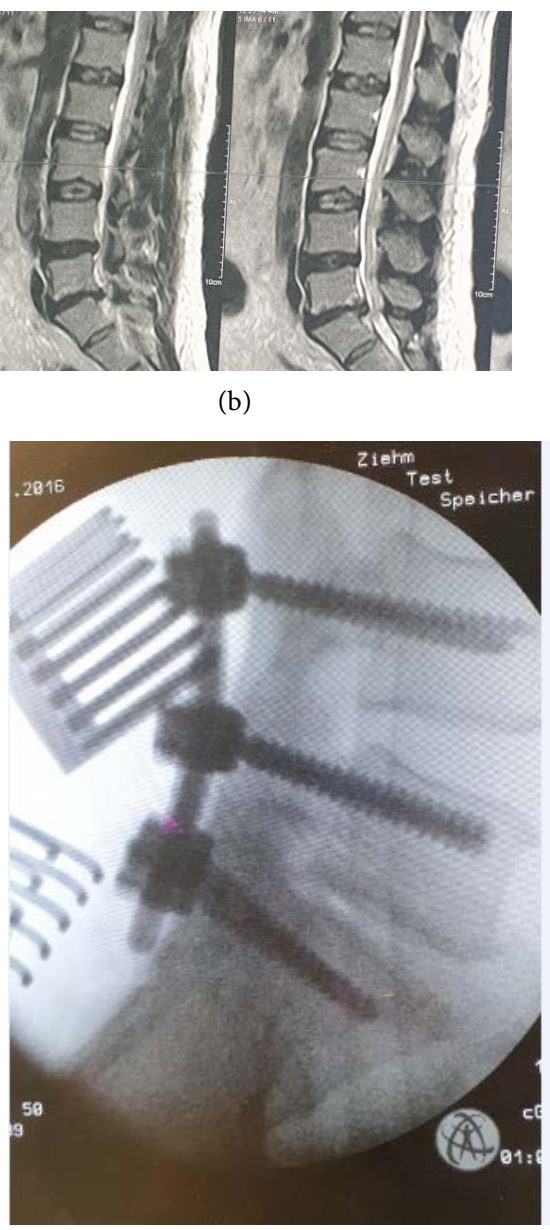

(d)

(c)

Figure 1. (a) Lumbosacral spine, T2 Axial view revealing lumbar disc prolapsed centrally and on right side, (b) MRI Lumbosacral spine, T2 Saggittal view revealing lumbar disc prolapsed on L5-S1 and disc bulge on L4-5 with/retrolithesis L5-S1, (c) Dynamic X-ray lateral view revealing retrolithesis L5-S1, (d) Intra-operative lateral view X-ray by C-ARM after placement of transpedicular screws and rod system. 
and (Figure 2). All patients were assessed using the Oswestry Disability Questionnaire, walking distance, and VAS pain score. (A Mehra et al., 2008) [15] (Ludger Klimek et al., 2017) [16].

\subsection{Surgical Procedure}

We used general anesthesia in all operated patients. The patients were positioned on a spinal frame in the prone position, with the abdomen free and the spine flexed to open the inter-laminar spaces.PLF group underwent bilateral laminectomy and discectomy, followed by pedicle screw insertion under navigation and placement of small bone grafts (allograft) intertransverse on both sides. The PLIF technique includes performing a wide laminectomy and bilateral partial facetectomy to allow good visualization of nerve roots on both sides and aggressive removal of the intervertebral disc with decortications of endplates of both vertebral bodies. It involves placing two small bone graft spacers, with gentle retraction of the spinal nerves and neurologic structures, one graft on each side of the interbody space (right and left sides)and then transpedicular screws are inserted for immediate stabilization under imaging use C-arm.

\subsection{Outcomes and Follow-Up}

We collected operative data, including the amount the blood loss during operation

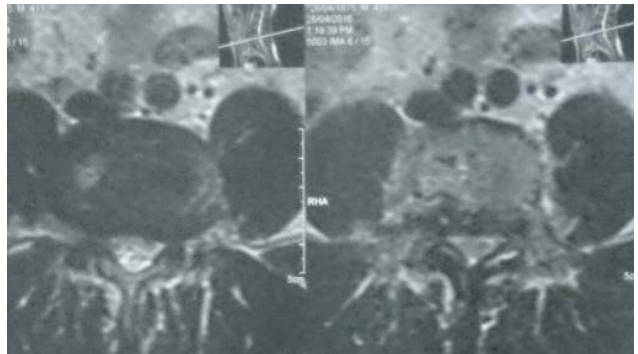

(a)

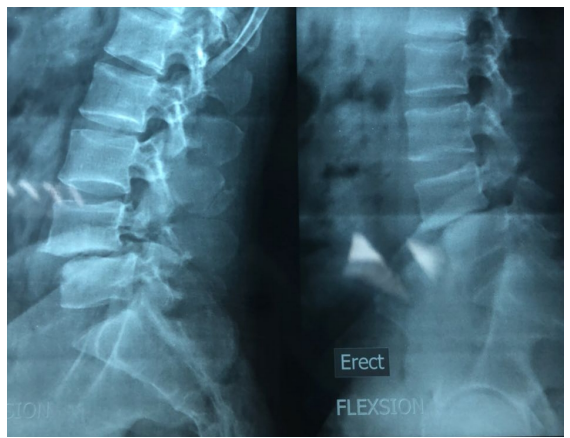

(c)

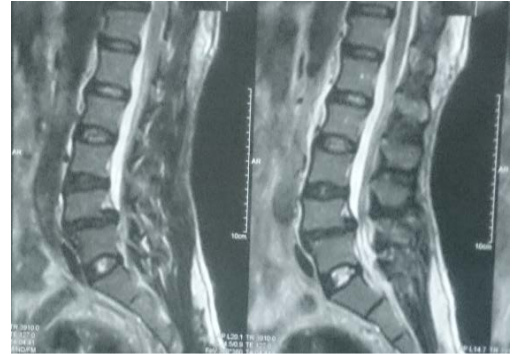

(b)

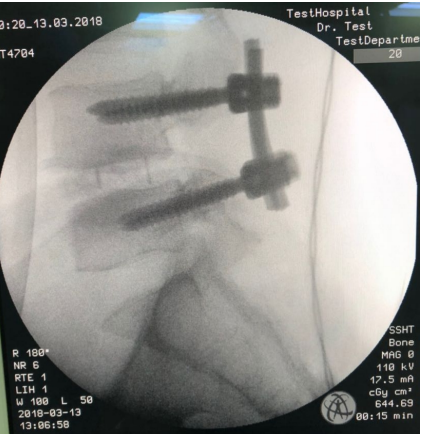

(d)

Figure 2. (a) MRI Lumbosacral spine, T2 Axial view revealing Lumbar canal stenosis (in two films beside each other), (b) MRI Lumbosacral spine, T2 Saggittal view revealing L4-5 Lumbar disc prolpase with canal stenosis (in two films beside each other) (c) Dynamic $\mathrm{X}$-ray Lumbosacral, Lateral view (in two films beside each other) revealing spondylolithesis grade 2 L4-5, (d) Post-operative X-ray with A-P and lateral views of revealing one level fixation of L4-5 and interbody Cage. 
and operative duration. We followed our patients in the immediate postoperative phase (for post-operative complications), one month, 3 months, 6 months (for pain and arthrodesis), and one year(for arthrodesis) after surgery with clinical examination and follow-up, using $\mathrm{x}$ ray and CT scan if needed.

\subsection{Statistical Analysis}

The collected data were analyzed using Statistical Package for Social Science (SPSS version 25 for windows, IBM, Chicago, IL). Data were summarized as mean \pm standard deviation. Categorical data were displayed as frequency and percentage. We used the Student's $t$ test to assess the statistical significance of the difference between two study group means.

\section{Results}

Thirty-eight patients were enrolled in the current study (19 in each group). The mean age for all participants was $50.16 \pm 8.44$ years and the overall sample size included 25 (65.8\%) males and 13 (34.2\%) females. The majority (81.6\%) of patients presented with back pain plus sciatica and required two levels of fixation (65.8\%). The mean pre-operative VAS score for all participants was $8.29 \pm 0.61$. Only three patients had muscle weakness grade 3 before surgery, while other patients had no muscle weakness detected (92.1\%). We detected no significant differences between both groups in terms of age $(p=0.57)$, sex $(p=0.73)$, clinical presentation $(p=1)$, required levels of fixation $(p=1)$, pre-operative VAS score $(\mathrm{p}=0.43)$ or muscle weakness $(\mathrm{p}=1)$. Data for both groups are summarized in Table 1.

Table 1. Baseline data of the compared PLF and PLIF groups.

\begin{tabular}{cccc}
\hline & Group A (PLF), N=19 & Group B (PLIF), N = 19 & $P$ \\
\hline Age (Year), Mean \pm SD & $49.37 \pm 7.71$ & $50.95 \pm 9.25$ & 0.57 \\
Sex & & & \\
Male & $12(48 \%)$ & $13(52 \%)$ & 0.73 \\
Female & $7(53.8 \%)$ & $6(46.2 \%)$ & \\
Clinical picture & & & 1 \\
Back Pain & $2(50 \%)$ & $2(50 \%)$ & \\
Back pain + sciatica & $16(51.6 \%)$ & $15(48.4 \%)$ & 0.43 \\
Weakness & $1(33.3 \%)$ & $2(66.7 \%)$ & \\
Pain (VAS score ) pre & $8.21 \pm 0.71$ & $8.37 \pm 0.5$ & \\
Muscle weakness pre & $18(51.4 \%)$ & & \\
No & $1(33.3 \%)$ & $17(48.6 \%)$ & \\
Grade III & & $2(66.7 \%)$ & \\
Number of levels & $13(68.4 \%)$ & $6(31.6 \%)$ & \\
One level & $1(5.3 \%)$ & $12(63.2 \%)$ & $0(0 \%)$ \\
Two levels & & &
\end{tabular}

Data are frequency and percentage, unless otherwise indicated. 
The mean operative duration in all participants was $3.34 \pm 0.74$ hours and the mean blood loss amount was $488.2 \pm 155.3 \mathrm{ml}$. We detected differences between the two groups in terms of blood loss amount $(\mathrm{p}=0.24)$; and the operative duration was significantly longer $(\mathrm{p}<0.001)$ in the PLIF group (Table 2 ).

Post-operative data for the comparison groups: (Table 3 ) The overall VAS score was reduced from $8.29 \pm 0.61$ (pre-operative) to $3.21 \pm 1.1$ ( 1 month post-operative) to $1.82 \pm 1.04$ (6 months post-operative).We detected no significant differences between the two groups at either time points ( $\mathrm{p}=0.56$ and 0.44 , respectively); After the operation, only three patients $(7.9 \%)$ have residual muscle weakness. The majority of patients $(\mathrm{N}=32,81.6 \%)$ did not suffer any complications related to the surgery. CSF leak was reported in only two patients, while back pain, screw break down, wound infection, and nerve root compression during cage insertion were reported in one patient each. No significant

Table 2. Intra-operative data of the compared PLF and PLIF groups.

\begin{tabular}{cccc}
\hline & Group A (PLF) & Group B (PLIF) & $P$ \\
\hline Blood loss (ml) & $457 \pm 193.8$ & $515 \pm 100.3$ & 0.24 \\
Operative time (Hr.) & $2.8 \pm 0.5$ & $3.9 \pm 0.5$ & $<0.001$ \\
\hline
\end{tabular}

Data are means \pm standard deviation.

Table 3. Post-operative data of the compared PLF and PLIF groups.

\begin{tabular}{|c|c|c|c|}
\hline & $\begin{array}{c}\text { Group A (PLF), } \\
\qquad N=19\end{array}$ & $\begin{array}{c}\text { Group B (PLIF), } \\
\qquad N=19\end{array}$ & $\mathbf{P}$ \\
\hline \multicolumn{4}{|l|}{ Pain (VAS score ), mean $\pm S D$} \\
\hline 1 month post-operative & $3.11 \pm 1.1$ & $3.32 \pm 1.1$ & 0.56 \\
\hline 6 months post-operative & $1.95 \pm 1.3$ & $1.68 \pm 0.7$ & 0.44 \\
\hline \multicolumn{4}{|l|}{ Muscle weakness post-operative } \\
\hline No & $18(94.7 \%)$ & $17(89.5 \%)$ & 1 \\
\hline Grade 5- & $1(5.3 \%)$ & $2(10.5 \%)$ & \\
\hline \multicolumn{4}{|l|}{ Complication } \\
\hline No & $15(79 \%)$ & $17(89.5 \%)$ & \multirow{7}{*}{1} \\
\hline CSF leak & $1(5.2 \%)$ & $1(5.2 \%)$ & \\
\hline Back Pain & $1(5.2 \%)$ & $0(0 \%)$ & \\
\hline Break down of one screw & $1(5.2 \%)$ & $0(0 \%)$ & \\
\hline Wound infection & $1(5.2 \%)$ & $0(0 \%)$ & \\
\hline Compression of nerve root with pedicle screw & $0(0 \%)$ & $1(5.2 \%)$ & \\
\hline Nerve root compression during cage insertion & $0(0 \%)$ & $1(5.2 \%)$ & \\
\hline \multicolumn{4}{|l|}{ Arthrodesis after 6 months } \\
\hline No & $7(36.8 \%)$ & $3(15.8 \%)$ & 0.14 \\
\hline Yes & $12(63.2 \%)$ & $16(84.2 \%)$ & \\
\hline \multicolumn{4}{|l|}{ Arthrodesis after 1 year } \\
\hline No & $1(5.2 \%)$ & $0(0 \%)$ & 1 \\
\hline Yes & $18(94.8 \%)$ & $19(100 \%)$ & \\
\hline
\end{tabular}


differences were noted between the two groups in terms of the incidence of muscle weakness $(\mathrm{p}=1)$ and complications $(\mathrm{p}=1)$, post-operatively. Arthrodesis occurred in 28 patients $(73.7 \%)$ six months after the procedure and in $37 \mathrm{pa}-$ tients (97.4\%) 12 months after the procedure. Both groups were comparable for pain post operative after one, six months according to VAS score Figure 3. Radiologically there is a potential advantage of PLIF over PLF to restore lumbar lordosis. Post operative hospital stay and post operative analgesia are the same in both types. In PLIF the cost is more than PLF due to price of the cage that used.

\section{Discussion}

In our study we discuss the surgical treatment for spondylolithesis and the goal of surgery is to decompress the neural elements and immobilize the unstable segment or segments of the spinal column. This is usually performed with elimination of motion across the facet joint and the intervertebral disc through arthrodesis according to Yan et al. and in our study surgical treatment was done by two modalities, transpedicular screws with PLF and transpedicular screws with PLIF.

Chronic back pain was the most commonly and early presentation according to Monica Lara-Alumina et al. [17] and the same was in this study as all patients in this study presented with back pain besides neurological compromization ranging from sciatica to neurological deficit.

Historically there has been male predominance in the incidence of lumbar surgery ranging from 1.3 to 2.1. According to Fox MW et al. [18] and the same was in this study with $65 \%$ male against $35 \%$ in whole group.

In our study we noticed that operative time is more in case of PLIF than that of PLF. The mean operative time in PLIF is 249 minutes while in PLF is 177 minutes.

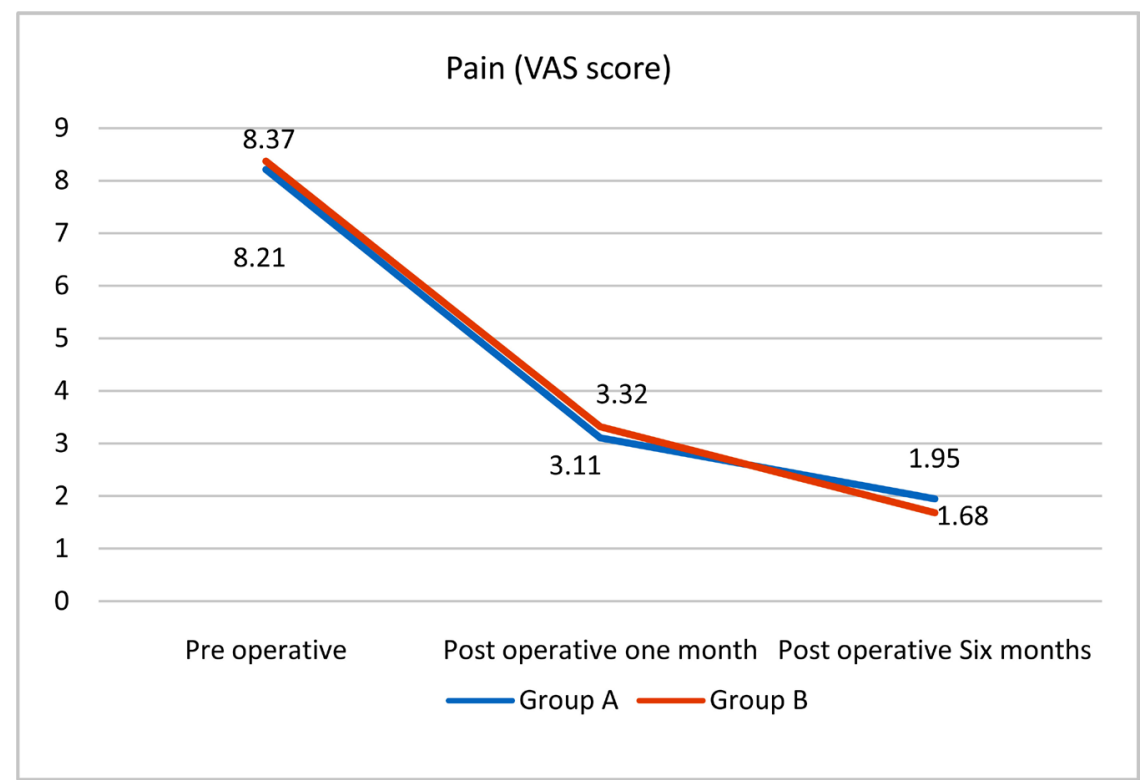

Figure 3. Pain according to VAS score in the two groups post operative one and six months follow-up (Ludger Klimek et al., 2017) [16]. 
In our study we noticed that operative blood loss in PLF is $457 \mathrm{ml}$ in average while in PLIF is $515 \mathrm{ml}$ in average which mean that operation in PLIF is more bloody, may be due to much more time of the operation and nature of more extensive technique of the operation.

The current study showed no significant differences in terms of all post-operative outcomes, including pain, muscle weakness, the rates of arthrodesis at 6 and 12 months, as well as the incidence of complications. However, the operative duration was significantly longer in the PLIF group, compared to the PLF group and blood loss was more in PLIF group compared to PLF group.

The observed results in this study are in line with some previous publications. For example, a former randomized study (Swedish Lumbar Spine Study) that included a similar number of patients $(\mathrm{N}=19)$ in the PLIF group and reported no difference in operative and functional outcomes in favor of the PLIF group [11]. Similar findings were reported by Kim et al. [12], Videbaek et al. [13], Cheng et al. [10], Ekman et al. [19], and Madan et al. [20]. In a systematic review of 29 high-quality studies by Jacobs et al., the authors reported no significant differences between various fusion techniques [14]. However it is contradictory to published results by Dantas et al. [21]. Similarly, the increased operative duration in the PLIF group is consistent with previous reports in the literature [10] [19].

However, we found no significant difference between the two groups in terms of post-operative complications. This is in discordance with previous studies by Fritzell et al. [11] and Maden et al. [20] who showed more complications in the PLIF group in comparison to the PLF group and attributed this finding to the more invasive nature, extensive dissection, and prolonged operative duration in the PLIF group. These contradictory findings may be attributed to the different sample size and expertise of the involved surgeons. Although PLIF may be considered a difficult procedure, but in the hands of experienced surgeons, it should not cause more technical problems than PLF. In our study, only two patients in the PLIF group developed nerve root compression with pedicle screw or due to cage insertion.

The rates of arthrodesis were (as expected) higher in the PLIF group than in the PLF group at six and 12 months, respectively. However, these differences were not statistically significant. An interesting finding in the literature is the lack of correlation between fusion rate (arthrodesis) and functional/clinical outcome [22] [23] [24]. This may be because different factors may affect the latter outcomes other than the fusion rate, such as economic factors (e.g. employment status and failure to return to work), as well as pre-operative factors (e.g. bone quality, lifestyle, duration of hospital stay, and the use of brace therapy) [1] [24].

This study has some strength points as the similar baseline characteristics between the two groups and that no patients were lost to follow-up over its one-year duration. However, it may be criticized for its relatively low sample size and relatively short follow-up duration compared to previous studies. Further, 
we did not measure the impact of both surgical procedures on the patients' quality of life following the surgery. These outcomes are usually under-investigated and should be assigned more value in the upcoming studies. Moreover, longer follow-up periods are needed to establish the comparison between both procedures on the long term.

\section{Conclusion}

In our comparative study, we achieved comparison between pedicle screw fixation with lateral fusion alone (PLF) in compare with pedicle screw fixation with inter body fusion (PLIF). Results indicate better results of fusion rate in PLIF while slightly higher rate of complication incidence mainly never compromises and also it is still more time consuming in the theater and more blood loss in the operation than Posterolateral fusion (PLF).

\section{Conflicts of Interest}

The authors declare no conflicts of interest regarding the publication of this paper.

\section{References}

[1] Rasomoff, H.L. and Rasomoff, R.S. (1985) Aggressive Nonsurgical Management of Pain in Degenerative Disease of the Spine. Principles of Spinal Surgery, 1, 645-656.

[2] Steiger, F., Becker, H.-J., Standaert, C.J., Balague, F., Vader, J.-P., Porchet, F., et al. (2014) Surgery in Lumbar Degenerative Spondylolisthesis: Indications, Outcomes and Complications. A Systematic Review. European Spine Journal, 23, 945-973. https://doi.org/10.1007/s00586-013-3144-3

[3] Sudo, H., Oda, I., Abumi, K., Ito, M., Kotani, Y. and Minami, A. (2006) Biomechanical Study on the Effect of Five Different Lumbar Reconstruction Techniques on Adjacent-Level Intradiscal Pressure and Lamina Strain. Journal of Neurosurgery, 5, 150-155. https://doi.org/10.3171/spi.2006.5.2.150

[4] Brantigan, J.W. and Neidre, A. (2003) Achievement of Normal Sagittal Plane Alignment Using a Wedged Carbon Fiber Reinforced Polymer Fusion Cage in Treatment of Spondylolisthesis. The Spine Journal, 3, 186-196. https://doi.org/10.1016/S1529-9430(02)00536-3

[5] Arai, Y., Takahashi, M., Kurosawa, H. and Shitoto, K. (2002) Comparative Study of Iliac Bone Graft and Carbon Cage with Local Bone Graft in Posterior Lumbar Interbody Fusion. Journal of Orthopaedic Surgery, 10, 1-7. https://doi.org/10.1177/230949900201000102

[6] Molinari, R.W., Sloboda, J.F. and Arrington, E.C. (2005) Low-Grade Isthmic Spondylolisthesis Treated with Instrumented Posterior Lumbar Interbody Fusion in US Servicemen. Journal of Spinal Disorders \& Techniques, 18, S24-S29. https://doi.org/10.1097/01.bsd.0000140197.07619.8b

[7] McAfee, P.C., DeVine, J.G., Chaput, C.D., Prybis, B.G., Fedder, I.L., Cunningham, B.W., et al. (2005) The Indications for Interbody Fusion Cages in the Treatment of Spondylolisthesis: Analysis of 120 Cases. Spine, 30, S60-S65. https://doi.org/10.1097/01.brs.0000155578.62680.dd

[8] Dehoux, E., Fourati, E., Madi, K., Reddy, B. and Segal, P. (2004) Posterolateral Ver- 
sus Interbody Fusion in Isthmic Spondylolisthesis: Functional Results in 52 Cases with a Minimum Follow-up of 6 Years. Acta Orthopaedica Belgica, 70, 578-582.

[9] Suk, S.-I., Lee, C.-K., Kim, W.-J., Lee, J.-H., Cho, K.-J. and Kim, H.-G. (1997) Adding Posterior Lumbar Interbody Fusion to Pedicle Screw Fixation and Posterolateral Fusion after Decompression in Spondylolytic Spondylolisthesis. Spine, 22, 210-219. https://doi.org/10.1097/00007632-199701150-00016

[10] Cheng, L., Nie, L. and Zhang, L. (2009) Posterior Lumbar Interbody Fusion versus Posterolateral Fusion in Spondylolisthesis: A Prospective Controlled Study in the Han Nationality. International Orthopaedics, 33, 1043-1047. https://doi.org/10.1007/s00264-008-0588-x

[11] Fritzell, P., Hägg, O., Wessberg, P. and Nordwall, A. (2002) Chronic Low Back Pain and Fusion: A Comparison of Three Surgical Techniques: A Prospective Multicenter Randomized Study from the Swedish Lumbar Spine Study Group. Spine, 27, 1131-1141. https://doi.org/10.1097/00007632-200206010-00002

[12] Kim, K.-T., Lee, S.-H., Lee, Y.-H., Bae, S.-C. and Suk, K.-S. (2006) Clinical Outcomes of 3 Fusion Methods through the Posterior Approach in the Lumbar Spine. Spine, 31, 1351-1357. https://doi.org/10.1097/01.brs.0000218635.14571.55

[13] Videbaek, T.S., Christensen, F.B., Soegaard, R., Hansen, E.S., Høy, K., Helmig, P., et al. (2006) Circumferential Fusion Improves Outcome in Comparison with Instrumented Posterolateral Fusion: Long-Term Results of a Randomized Clinical Trial. Spine, 31, 2875-2880. https://doi.org/10.1097/01.brs.0000247793.99827.b7

[14] Jacobs, W.C.H., Vreeling, A. and De Kleuver, M. (2006) Fusion for Low-Grade Adult Isthmic Spondylolisthesis: A Systematic Review of the Literature. European Spine Journal, 15, 391-402. https://doi.org/10.1007/s00586-005-1021-4

[15] Mehra, A., Baker, D., Disney, S. and Pynsent, P.B. (2008) Oswestry Disability Index Scoring Made Easy. Annals of the Royal College of Surgeons of England, 90, 497-499. https://doi.org/10.1308/003588408X300984

[16] Klimek, L., Bergmann, K.-C., Biedermann, T., Bousquet, J., et al. (2017) Visual Analogue (VAS): Measuring Instruments for the Documentation of Symptoms and Therapy Monitoring in Cases of Allergic Rhinitis in Everyday Health Care. Allergo Journal International, 26, 16-24. https://doi.org/10.1007/s40629-016-0006-7

[17] Lara-Almunia, M., Gomez-Moreta, J.A. and Hernandez-Vicente, J. (2015) Posterior Lumbar Interbody Fusion with Instrumented Posterolateral Fusion in Adult Spondylolisthesis: Description and Association of Clinico-Surgical Variables with Prognosis in a Series of 36 Cases. International Journal of Spine Surgery, 9, 22. https://doi.org/10.14444/2022

[18] Fox, M.W., Onofrio, B.M., Onofrio, B.M. and Hanssen, A.D. (1996) Clinical Outcome and Clinical Instability Following Decompressive Lumbar Laminectomy for Degenerative Spinal Stenosis: A Comparison of Patients Undergoing Concomitant Arthrodesis versus Decompression Alone. Journal of Neurosurgery, 85, 793-802. https://doi.org/10.3171/jns.1996.85.5.0793

[19] Ekman, P., Möller, H., Tullberg, T., Neumann, P. and Hedlund, R. (2007) Posterior Lumbar Interbody Fusion versus Posterolateral Fusion in Adult Isthmic Spondylolisthesis. Spine, 32, 2178-2183. https://doi.org/10.1097/BRS.0b013e31814b1bd8

[20] Madan, S. and Boeree, N.R. (2002) Outcome of Posterior Lumbar Interbody Fusion versus Posterolateral Fusion for Spondylolytic Spondylolisthesis. Spine, 27, 1536-1542. https://doi.org/10.1097/00007632-200207150-00011

[21] Dantas, F.L.R., Prandini, M.N. and Ferreira, M.A.T. (2007) Comparison between Posterior Lumbar Fusion with Pedicle Screws and Posterior Lumbar Interbody Fu- 
sion with Pedicle Screws in Adult Spondylolisthesis. Arquivos de Neuro-Psiquiatria, 65, 764-770. https://doi.org/10.1590/S0004-282X2007000500006

[22] Möller, J., Wittenberg, R.H., Nolte, L.P., Jergas, M., Willburger, R. and Krämer, J. (1992) Results of Lumbosacral Distraction Spondylodesis for the Treatment of Spondylolisthesis, Failed-Back Syndrome, and Lumbar Instability. European Spine Journal, 1, 117-124. https://doi.org/10.1007/BF00300938

[23] O’Beirne, J., O’Neill, D., Gallagher, J. and Williams, D.H. (1992) Spinal Fusion for Back Pain: A Clinical and Radiological Review. Journal of Spinal Disorders, 5, 32-38. https://doi.org/10.1097/00002517-199203000-00005

[24] Schnee, C.L., Freese, A. and Ansell, L.V. (1997) Outcome Analysis for Adults with Spondylolisthesis Treated with Posterolateral Fusion and Transpedicular Screw Fixation. Journal of Neurosurgery, 86, 56-63.

https://doi.org/10.3171/jns.1997.86.1.0056

\section{Abbreviations}

CSF: Cerebrospinal fluid

PLIF: Posterior lumbar interbody fusion

PLF: posterolateral lumbar fusion

VAS: Visual analogue scale 